\title{
From therapeutic patient education principles to educative attitude: the perceptions of health care professionals - a pragmatic approach for defining competencies and resources
}

\author{
This article was published in the following Dove Press journal: \\ Patient Preference and Adherence \\ 22 March 2017 \\ Number of times this article has been viewed
}

\author{
Benoit Pétré \\ Remi Gagnayre ${ }^{2}$ \\ Vincent De Andrade ${ }^{2}$ \\ Olivier Ziegler ${ }^{3}$ \\ Michèle Guillaume' \\ 'Department of Public Health, \\ University of Liège, Liège, Belgium; \\ ${ }^{2}$ Educations and Health Practices \\ Laboratory (LEPS), (EA 34I2), UFR \\ SMBH, Paris 13 University, Sorbonne \\ Paris Cite, Bobigny, ${ }^{3}$ Department \\ of Diabetes, Metabolic diseases \\ and Nutrition, Nancy University \\ Hospital, Nancy, France
}

\begin{abstract}
Educative attitude is an essential, if implicit, aspect of training to acquire competency in therapeutic patient education (TPE). With multiple (or nonexistent) definitions in the literature, however, the concept needs clarification. The primary aim of this study was to analyze the representations and transformations experienced by health care professionals in the course of TPE training in order to characterize educative attitude. We conducted an exploratory qualitative study using several narrative research-based tools with participants of two TPE continuing education courses. We then performed an inductive thematic analysis. Thirty-three people participated in the study; the majority were women $(n=29)$, nurses $(n=17)$ working in a hospital setting $(n=28)$. Seven categories of statements were identified: time-related ("the right moment, how much time it takes"), the benefits of TPE (to health care professionals' personal well-being), emotions and feelings (quality of exchanges, sharing), the professional nature of TPE (educational competencies required), the holistic, interdisciplinary approach (complexity of the person and value of teamwork), the educational nature of the care relationship (education an integral part of care) and the ethical dimension (introspection essential). The first three components appear fairly innovative, at least in formulation. The study's originality rests primarily in its choice of participants - highly motivated novices who expressed themselves in a completely nontheoretical way. Health models see attitude as critical for adopting a behavior. Best TPE practices should encourage personal work on this, opening professionals to the social, experiential and emotional aspects of managing chronic illness.
\end{abstract}

Keywords: therapeutic patient education, attitude of health personnel, competence, professional

\section{Key messages}

Attitudes are important components of competencies.

The attitudinal component of educative competencies, called "educative attitude", requires further characterization in the field of therapeutic patient education (TPE).

Seven dimensions and 43 statements of educative attitude were highlighted in this study. They are related to temporal aspect, personal benefit of TPE practice for health care professionals, emotional dimension, holistic and interdisciplinary approach to the patient, the professionalizing nature of TPE, educational relationship between the patient and caregiver, and ethical relationship.

The statements of educative attitude have to be considered as part of health care professional training in TPE field and as a tool to clarify the reasons for any tensions between health care professionals in the same team.

Further studies are needed to validate educative attitude statements and to better understand how to develop them.
Correspondence: Benoit Pétré Department of Public Health, University of Liège, Quartier Hôpital, Avenue Hippocrate 13 (B23), 4000 Liège, Belgium Tel +32 43662505 Fax +3243662596

Email benoit.petre@ulg.ac.be 


\section{Introduction}

Since 1998, therapeutic patient education (TPE) has been recognized as a significant contribution to chronic disease management that should be incorporated into health care professional (HP) training programs. ${ }^{1,2}$ TPE is based on the powerful idea that educating patients - that is, helping them develop skills to better manage, and adapt their lives to, their disease - contributes to health.

The quality of TPE activities depends heavily on the skills and abilities of HPs, ${ }^{3}$ the most important being educational competency. Competency is defined as knowing how to take effective action through the mobilization and use of a variety of resources. ${ }^{4}$ The term "resource" is preferred to "knowledge" because it can encompass social, emotional and experiential, rather than just cognitive, elements. Combining such resources in a given professional situation leads to action. The recommendations regarding TPE competencies ${ }^{1,5}$ refer only to resources in the domain of knowledge and know-how. Yet, as Ajzen's theory of planned behavior ${ }^{6}$ tells us, attitudes influence - and strongly predict - behavior. Thus, the attitudinal aspect of educational competency henceforth referred to as "educative attitude" - is crucial for the development of TPE competencies, allowing as it does for the social, emotional and experiential dimensions of the aforementioned resources.

This is a relatively important consideration from the standpoint of professional practice, where "educative attitude" is often used without knowing to what exactly it refers. Indeed, "educative attitude" can mean different things depending on the country or context in which it is used, leading to different opinions on which competencies should be acquired. A conceptual clarification is therefore needed.

A number of definitions for attitude have been proposed in the literature. Rosenberg and Hovland ${ }^{7}$ described attitude, in a broad sense, as "predispositions to respond to some class of stimuli with certain classes of response." Viewed in that way, they felt that attitude has three basic components: cognitive, affective and behavioral. Other authors have offered narrower definitions based on the idea that the cognitive and behavioral components ultimately derive from underlying affects and beliefs. ${ }^{8}$ Eagly and Chaiken, ${ }^{9}$ for example, defined attitude as a "psychological tendency that is expressed by evaluating a particular entity with some degree of favor or disfavor". That definition helps clarify the concept based on three features: psychological tendency (attitude is a state of mind), evaluation (the individual makes a value judgment) and attitude object (the evaluative response is directed at specific entities or things - an idea, a person or other entities). ${ }^{10}$ Because it includes aspects of attitude that are missing from competency resources in the field, this definition is especially useful with regard to TPE. Several studies offered further food for thought on this subject. (The literature search was broadened to include the concepts of self-management and self-care. Though these concepts do not always cover the same reality as TPE, these search terms retrieve studies that better fit our research aims.)

The literature review on educative attitude helped identify, first, articles on practices and barriers to self-care or TPE $^{11-15}$ and those that emphasized the difficulties in transferring practices, the lack of time for TPE, the difficulties in handling psychosocial issues, communication with the patient and the lack of support and structure for such work. Those studies do not, however, explore the attitudinal aspect as described by Eagly and Chaiken. ${ }^{9}$

A few studies were closer to what we were looking for and attempted to explore the concept of attitude as it relates to TPE or self-care using a qualitative approach. Hult et al ${ }^{16}$ focused on the degree to which HPs recognize their role as educators; it seemed fairly slight among the professionals interviewed. Thorne et $\mathrm{al}^{17}$ looked at the attitudes and values underlying health care relationships in the context of chronic illness, using patient expectations to indirectly explore professionals' attitudes. The patients identified the need for their HP to recognize their (the patients') expertise and skills, to see them as a whole person rather than just a disease, to share information with them and to prioritize quality of life. Bos-Touwen et a ${ }^{18}$ demonstrated the importance of recognizing patients' ability to take care of themselves as a factor affecting self-care practices and nurses' overall assessment of patients. Norris and Kilbride ${ }^{19}$ pointed out the perceived challenge that patient empowerment and the loss of control inherent in that type of approach poses to HPs. Lake and Staiger ${ }^{20}$ reported that HPs rely on five main elements for implementing self-management: collaborative care, self-responsibility, the client's individual situation, structured support and linking with community agencies. Clark et $\mathrm{al}^{21}$ found that HPs involved in TPE felt that it led to greater health care team well-being. These results confirm the multidimensional character of educative attitude in the TPE or self-care approach. Moreover, these studies were based on HPs not necessarily trained in TPE. While the results are interesting, such professionals may have a truncated view of TPE and self-care and, as a result, a narrow or truncated view of educative attitude itself. Apropos of this, Roussel and Deccache ${ }^{22}$ showed that HPs have multiple, sometimes conflicting, representations of TPE. 
Other types of studies focused on the assessment aspect, proposing scales for evaluating attitude. The Diabetes Attitude Scale (DAS), by Anderson et al, ${ }^{23}$ can be used to measure professionals' attitudes about the need for special training to provide diabetes care, the severity of type 2 diabetes, the value of tight glucose control, the psychosocial impact of diabetes and patient autonomy. Hibbard et $\mathrm{al}^{24}$ proposed the Clinician Support for Patient Activation Measure (CS-PAM), which assesses health care professionals' attitude about the importance of patient self-management skills. Linn and Lewis $^{25}$ developed a scale to measure attitude toward self-care relative to perceived access, quality, cost and results of selfcare. Finally, Garvey et $\mathrm{al}^{26}$ proposed a scale for measuring the attitudes of health care personnel providing general hospital care to people with learning disabilities. The scale includes items regarding the emotions associated with caring for this particular group and the competencies that caregiver teams need to provide such care. These tools are interesting in that they offer a quantitative view of the situation and allow comparisons over time (eg, before and after a training program) or between populations. Their biggest limitation, however, is that they are oriented toward a specific component of attitude or a particular audience or pathology. These kinds of tools fail to allow all the possible aspects of attitude that might be considered given the previously described results.

To describe the different dimensions of educative attitude more explicitly, the focus needs to be narrowed to HPs trained in TPE; they share a broader view of attitude and require a more qualitative approach. To the best of our knowledge, only one study ${ }^{27}$ used an open-ended approach to explore the perceptions of HPs who had taken an online TPE course. The results of that study showed how important it was that HPs recognize patient-caregiver equality, the need for patientcentered care in which HPs support patient self-management. The study pointed out the need for further research to better characterize educative attitude, while placing it in the context in which it is expressed. The advantage of using a group of trainee HPs in this kind of study is that they are naive, honest and motivated in their responses.

Based on these observations, the main objective of our study was to explore the perceptions and opinions of HPs engaged in the training process, in order to characterize the educative attitude in the field of TPE.

\section{Methods}

Approach

Educative attitude was characterized based on the views of HPs engaged in a TPE training program. We took a qualitative exploratory approach using a combination of narrative research-inspired data collection instruments. ${ }^{28}$

\section{Population and sample}

Two training sites were studied - Liege (Belgium) and Nancy (France). By looking at two different training systems, we were able to explore educative attitude in different contexts. In France, TPE is required by the public health code, and implementation is guided by best practice recommendations. In Belgium, on the other hand, there is no official policy for the development of TPE. The advantage in studying these two sites was not the ability to compare the responses from the two samples but better data saturation. The main characteristics of the two training programs are described in Table 1. Health care professionals were chosen by convenience sampling. All the individuals who participated in the 2014-2015 courses at the two training sites were invited to participate in this study.

\section{Data collection}

Three types of tools were used to collect information related to the study objectives, using the process shown in Figure 1.

The process began with the most open-ended, nonspecific approach possible to educative attitude and ended with the construction of a semistructured questionnaire, with an intermediate phase in between. The reflective analysis - originally intended for certifying the Belgian HPs - served to identify the initial features of educative attitude in the most spontaneous possible way. This enabled the investigators to better target the study parameters, which were then collected using an open-ended questionnaire administered to both groups. Finally, the researchers developed a third tool to get more detailed information by presenting the various dimensions of educative attitude to the respondents. Therefore, three rounds of data collection, from January 2015 to June 2015, were carried out with the respondents. This iterative process is highly recommended in qualitative research. Overall, the instructions communicated to the participants were to write about "how the training has changed their mind about patient role, about professional practices, $[\ldots]$ "

\section{Data analysis}

The participant narratives were read in their entirety. The principal investigator (BP) then extracted all quotations (sentences or paragraphs) that fit our study objectives, verbatim, preserving the quality of the writings as produced. Those quotations were compiled into content-similar groups 
Table I Description of the training programs

\begin{tabular}{|c|c|c|}
\hline $\begin{array}{l}\text { Characteristics } \\
\text { of programs }\end{array}$ & Liege training (Belgium) & Nancy training (France) \\
\hline Duration & I year & I year \\
\hline $\begin{array}{l}\text { Number of } \\
\text { sessions }\end{array}$ & 14 days & 14 days \\
\hline Total number & 120 hours & 112 hours \\
\hline
\end{tabular}

Total number $\quad 120$ hours
of hours

Main objectives - To provide an introspective approach to their practices and their representations.

- To develop a rigorous methodology that can lead to construction of a single TPE course for each patient.

- To center the support on the patient's situation from the perspective of systemic approach of the person.

- To work in a team, coordinating its work with other actors in the management toward common patient-centered goals.

- To integrate TPE in care activities.

Main contents Module I: TPE: some ethics in our professional practices! What consequences for my practice? Module 2: Discovering the chronic patient Module 3: Learning to listen, communicate and talk: a good start in education

Module 4: Learning to listen: motivations, resources and limits: How to stay relevant? Module 5: Announcing the diagnosis: how to optimize?

Module 6: How to know my patients and their expectations better, in order to define appropriate goals? The educational diagnosis Module 7: A little method: definition, planning and implementation of learning teaching Module 8: Patient evaluation: a necessity

Educational options

Target audience Health practitioners in direct contact with

Training is based on a central pedagogical principle that constitutes the isomorphism: the idea is to teach how the TPE should be conducte with patients (use of active learning techniques, work on representations, centering on learner engagement experience of the learner, etc.). The evaluation test will consist of a personal work, based on analysis of clinical situations encountered by the participant. patients.

Requirements: higher education diploma

Maximum number 15

of participants

Training sponsor University of Liege (Faculty of Medicine)

More information http://www.facmed.ulg.ac.be/cms/c_1457759/frl certificat-d-universite-en-pratique-d-educationtherapeutique-du-patient
- To propose a comprehensive humanistic approach to patient care aimed at providing patients with the skills and strategies required to change their behavior, in order to improve the patient's health and, in particular, quality of life.

- To provide an integrated model of TPE in which significant emotional and behavioral needs of patients are met, ie, coherent interventions that center on the patients' needs, encouraging the coordination of the educational team and emphasizing patient's self-management.

- To improve relations between the caregiver and the patient using a fundamental redefinition of their respective roles: patients become partners and health care professionals become "coaches."

Module I: Main concepts and tools used in TPE

- Revisiting the concept of chronic disease. Quality of life. Pursuit of happiness

- TPE versus disease management.

- Motivation, self-management capabilities and self-efficacy, learned helplessness, readiness to change, self-determination theory

- Psychological distress and resilience. Sociocultural factors, economic insecurity

- Main principles of pedagogy: educational position between care and cure

- Health psychology: contribution to TPE

Module 2: Stages of education program development

- Individual assessment of patient's needs and resources; negotiation of objectives

- Personalized care planning viewed as a collaborative process in which patients and health care professional identify and discuss problems related to the patient's condition

- TPE integrated into routine care

- Educational individual or group sessions

- Role and management of the patient-centered interdisciplinary team

- Patient evaluation: acquisition of skills, experience with the disease, ability to cope, satisfaction; program evaluation: content and organization.

Active teaching methods are used for $\sim 40 \%$ of the program. Learning takes place through discoveries based on investigations, for example, case studies or role games. The training is based on a problem-solving approach.

Both experienced health care professionals and university professors are involved.

- Medical students or pharmacy students who have completed the second cycle

- Physicians and pharmacists

- Health care professionals who have completed a paramedical training: dietitians, physiotherapists, nurses, psychologists and podiatrists.

25

University of Lorraine (Medicine Faculty)

http://www.edulor-formation.frl

Abbreviation: TPE, therapeutic patient education. 


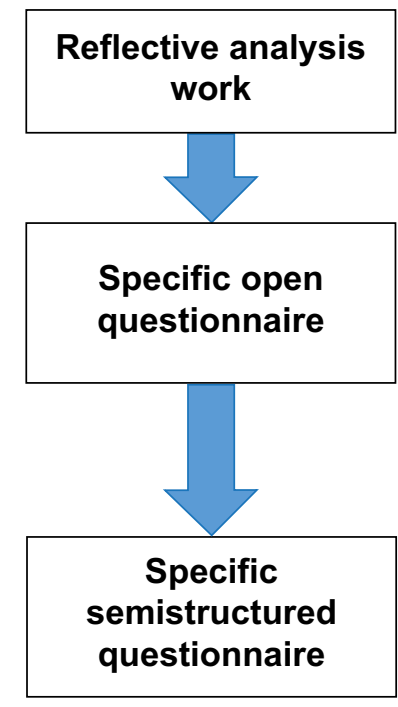

Data collection tool
Participants were asked to produce a reflective analysis work based on the contribution of individual course modules and structured as follows: initial situation, situation course module contribution, perspectives/practical implications.

Participants were asked to depict transformations induced by the different training modules, more specially the evolution of their state of mind during the training. Participants were also asked to identify causal attribution of those transformations (relative to the secondary objective of the study).

Participants were asked to specify the transformation of their state of mind according to five themes identified in the previous responses obtained in specific questionnaire.

Description of data collection tool
BE

FR

$X$

$\mathrm{X}$

$\mathrm{X}$

$x \quad x$

Respondents

Figure I The data collection process.

Abbreviations: BE, Belgium; FR, France.

called "codes" and then into broader groups called "themes". An iterative process was then performed. If a new code was introduced, all the narratives were read again to ensure that the data extraction was complete and to verify that the initial classification was accurate. Each narrative text was read several times. The result was then used to construct a preliminary analysis grid. Next, a second investigator (CC) classified a sample of 100 randomly chosen quotations. The rate of agreement between the two investigators in classifying the quotations was $71 \%$. The reasons for disagreement in classification were discussed, leading to a new analysis grid that was more accurate in terms of defining the desired themes. Two researchers (BP and CC) then independently analyzed another 100-quotation sample. That time, the rate of agreement between the two researchers was $87 \%$, which the study researchers deemed acceptable and in keeping with the general recommendations of $\sim 80 \%$ for this type of exploratory study. ${ }^{29}$ The principal investigator (BP) then classified all the quotations. For each theme, all the included quotations were synthesized to bring out the main ideas. Finally, the observations were expressed in the form of statements or propositions, which were used to construct a model for characterizing educative attitude. Content analysis of the raw data was used to create analysis categories in which a set of statements could be extracted. Those statements were submitted to the participants, who could agree or not with the statements and offer suggestions for reformulating them if they felt they were misunderstood or inaccurate.
As recommended by Miles and Huberman, ${ }^{30}$ several quality criteria were used to ensure the validity of the results and their interpretation:

- Triangulation: the protocol design, data collection and data analysis were collaborative. Though only one person (BP) ran the entire process, a four-person working group met regularly and offered comments on the conduct of the study

- Weighting: for each theme and subtheme, the number of quotations were counted to get a more precise idea of their importance

- Intercoder agreement: intercoder reliability was calculated and deemed acceptable $>80 \%$

- Theoretical validation: done by comparing the results with existing scientific data (refer the "Discussion" section)

- Participant validation of the statements characterizing educative attitude

- Collecting data from two groups being trained in different contexts helped yield better data saturation

\section{Ethical considerations}

The Comite d'Ethique Hospitalo-Facultaire Universitaire de Liege reviewed the study design and waived the requirements for ethical approval and patient written informed consent, given the nonintrusive nature of the questions and the lack of any anticipated personal or professional consequences for the HPs. Participation in the study was completely voluntary. The participants were informed that the information revealed would in no way affect their training process. All the HPs 
involved agreed to participate in the study. The participants' words were anonymized beginning with transcription. Only the principal investigator was able to connect the quotations to the identity of a participant.

\section{Results}

\section{Characteristics of the sample}

The characteristics of the study participants are shown in Table 2 . The majority were women, mainly dietitians and nurses employed in urban hospitals.

\section{Presentation of themes with examples}

Seven themes were ultimately identified. Each is presented with a description of its definition (what it means), a summary of the content provided by the participants and accompanied by quotations that illustrate that description (refer Boxes 1-7 for each theme). The weight of each theme was determined by the number of participants who discussed the theme or

Table 2 Description of the sample

\begin{tabular}{|c|c|}
\hline Characteristics & $n(N=33)$ \\
\hline \multicolumn{2}{|l|}{ Country } \\
\hline France & 20 \\
\hline Belgium & 13 \\
\hline \multicolumn{2}{|l|}{ Gender } \\
\hline Female & 29 \\
\hline Male & 4 \\
\hline \multicolumn{2}{|l|}{ Age (years) } \\
\hline $25-35$ & II \\
\hline $36-45$ & 10 \\
\hline $46-55$ & 12 \\
\hline \multicolumn{2}{|l|}{ Profession } \\
\hline Dietitian & 8 \\
\hline Nurse & 17 \\
\hline Physician & 3 \\
\hline Project coordinator & 2 \\
\hline Physiotherapist & 2 \\
\hline Pharmacist & I \\
\hline \multicolumn{2}{|l|}{ Work setting ${ }^{\mathrm{a}}$} \\
\hline Hospital & 25 \\
\hline Private office & 4 \\
\hline Health care network & 6 \\
\hline Nursing home & 3 \\
\hline Other & I \\
\hline \multicolumn{2}{|l|}{ Method of payment } \\
\hline Fee for services & I \\
\hline Employee & 28 \\
\hline Mixed & 4 \\
\hline \multicolumn{2}{|l|}{ Patient environment $\mathrm{t}^{\mathrm{b}}$} \\
\hline Urban & 27 \\
\hline Rural & 3 \\
\hline Mixed & 2 \\
\hline
\end{tabular}

Notes: aSeveral answers allowed. ${ }^{b}$ Data missing for one participant. subtheme and the corresponding number of quotations. The participant's gender, age and profession are in parentheses after each quotation. The quotations were translated from French to English by a native English speaker.

\section{Temporal aspect}

This refers to the way in which the HPs think about chronic illness in a long-term care relationship. The HPs stressed the importance of making time for activities such as informing patients of the diagnosis and describing the treatment plan. They talked about the need to make time to listen $(n=13,20$ quotations, $a$ and $b)$. Adapting the TPE to the patient's psychological readiness is an essential condition for success in TPE ( $n=7$, eight quotations, c). The professionals consider postponing educational activities an option if patients are not ready and feel that it is not always the right time for educational activities ( $n=4$, five quotations, $\mathrm{d}$ and e). The HPs understand that chronic illness involves a long-term relationship ( $\mathrm{n}=3$, four quotations, $\mathrm{f}$ ) (Box 1).

\section{Personal benefits of TPE practice for HPs}

This refers to the benefits of incorporating TPE into their professional practice. The HPs acknowledged that incorporating TPE into their professional practices allowed/legitimized

Box I Extracts relating to the temporal aspects of educative attitude

a. Before, it was important for me to give the patients something right from the beginning. There had to be nutritional information from the start and I only focused on nutritional advice. I was not in the least bit aware of the patient's perceptions and I never once thought that I had to pay attention to that. Shame on me! [Female, 38, project coordinator]

b. Aware that it is good to make time to listen and understand [Female, 33, nurse]

c. I became aware of the different stages of change. So if the patient is not ready, any attempt at support is bound to fail [Female, 43, dietitian]

d. Being able to admit sometimes that you cannot progress, or progress any further, but reassure the patient of your availability, let them take the time to reflect, invite them to contact you at a later date, if they feel the need [Female, 43, dietitian]

e. Seeing as they did not want to talk about their illness, at least for the moment, I decided to arrange to talk about it later [Female, 52, dietitian]

f. Longitudinal tracking and the chronicity of obesity provide another outlook. I think I said it several times. According to my view of obesity, chronicity was not present. I was looking at things from a curative point of view. You change your behavior, you lose weight, and then you can live "normally", "like before". I really had a simplistic view of things, for sure, because I was experiencing the situation from the inside, I was in denial to avoid having to change and say goodbye to behaviors that certainly only offered me secondary benefits [Female, 38, project coordinator] 
some professional activities that were previously considered informal (such as being open to learning about patients' lives; $n=6$, seven quotations, a), increased their motivation to work ( $\mathrm{n}=2$, two quotations), restored their capacity for action with the patient, thus enhancing their sense of competency and effectiveness ( $n=8,19$ quotations, $b$ and $c)$ or, more broadly, improved their quality of life $(n=1$, one quotation, d) (Box 2).

\section{Emotional dimension}

This refers to an awareness of the influence of psychological mechanisms underlying the relationship with the patient. The participants stressed the importance of consistency between their thoughts, their emotions and their actions and of being more natural with the patient ( $n=12,15$ quotations, a). The HPs became aware of the potential for projecting emotions that clinical situations elicited in them - the connection with their personal circumstances, in particular - and for contamination of the therapeutic relationship ( $n=11,24$ quotations, $b$ ). TPE also requires recognizing and welcoming patients' emotions ( $n=3$, three quotations, $c)$. The training changed the professionals' attitude and made them more careful and thoughtful with regard to their professional practice $(n=17$, 38 quotations, d). One participant stressed how valuable the training was in making her aware that resistance is an integral part of a patient's strategy for coping with illness $(n=1$, one quotation, e) (Box 3).

\section{The professionalizing nature of TPE}

This refers to the recognition that TPE demands a rigorous, scientific (professional) approach. The HPs recognized

Box 2 Extracts relating to the perceived benefits of educative attitude

a. This training allowed me to legitimize the fact of being able to discuss things other than food, to open up to the patient's real life thus allowing a relationship of trust to be established [Female, 38, project coordinator]

b. I think I have now finally moved on to the next step, I have overcome the barriers I set myself, I have succeeded in becoming active again, of being in charge of the situation [Female, 54, dietitian]

c. I now feel more competent, because I now realize that I can have an influence on the situation: I am no longer a passive spectator, I now have the tools to be an active player. I learnt to take control again of an aspect of my job that I was not able to before and this is undoubtedly one of the most impressive personal developments [...] [Female, 54, dietitian]

d. She also allowed me to discover that TPE can also improve the caregiver's quality of life! [Female, 43, dietitian]

Abbreviation: TPE, therapeutic patient education.
Box 3 Extracts relating to the emotional dimension of educative attitude

a. There was clearly an internal incoherence between what I was thinking, what I was doing and my emotional state (neurolinguistic programming) [Female, 40, nurse]

b. As a professional, we also have a personal and private life. It is therefore quite normal that some elements reported by the patient echo our own experiences. As a professional, you have to learn to listen to yourself and take a step back from the situations you experience in order to avoid a transference or countertransference, which would cloud the relationship that is in the process of forming [Female, 54, dietitian]

c. The patients' emotions frighten me less, I accept them. And I think that this helps me to better support them [Female, 48, nurse]

d. First of all, I would like to thank the whole teaching team who have enabled me to question myself and "make" me take a good deep look at my profession, my perceptions and the links between every behavior [Female, 38, project coordinator]

e. A new consideration of difficult, resistant patients, by distancing myself, taking a step back, in order to respect the times that are not favorable to education and to seek appropriate solutions [Female, 3I, dietitian]

that TPE activities require mental preparation based on a theoretical framework that helps give structure to their contacts or meetings with the patient ( $\mathrm{n}=7,14$ quotations, a). They recognized that TPE is more than just supplying information, which they considered insufficient for changing an individual's behavior ( $n=6$, nine quotations, $b$ ). They stressed the need for TPE-trained caregivers with real skills ( $n=6$, eight quotations, $c$ ). TPE helps structure and formalize previously informal practices ( $\mathrm{n}=5$, five quotations). TPE was felt to be a help in recognizing essential steps such as assessment and educational diagnosis as therapeutic acts $(n=4$, four quotations, d). The HPs recognized that the scientific process underpinning the TPE approach helped improve the quality and safety of care ( $n=2$, two quotations, e). Finally, they reported that TPE required specialized knowledge of the illness in question ( $n=1$, one quotation, $f$ ) (Box 4).

\section{Holistic, interdisciplinary approach to the patient}

This is the awareness that there are multiple causes of chronic disease that require the collaboration of different HPs. The HPs noted the importance of a holistic view of disease, recognizing the need for an environmental-biopsychosocial approach. Each person should be considered in the context of his history and living environment, to avoid a fragmented or reductionist approach ( $\mathrm{n}=23,46$ quotations, a). The HPs became more open to the two aims of TPE, that is, health and quality of life. The professionals were better able to see their education work, their objectives and the evaluation indicators in terms of these two aims ( $n=6,12$ quotations, $b$ ). 
Box 4 Extracts relating to the "professionalizing nature of TPE" aspect of educative attitude

a. I focus more efficiently on the structure of the interview, as suggested in the "Calgary Cambridge" model. This helps me to better "channel the talkative patient" and to already exchange reference points regarding the (physical, psychological, social) objectives to be set, what appropriate information to provide and the planning of the following steps [Female, 54, dietitian]

b. We think that we were providing education but in fact, are not we simply providing information, for instance by handing out brochures? [Female, 48, nurse]

c. Before educating the patient, we, the caregivers, need to be educated. Hence the value of training and continuing education, so that we are competent [Female, 37, nurse]

d. I must admit that as far as I am concerned, assessment was practically nonexistent. It simply consisted of a debriefing during the next session. I have become aware of its importance, so I fully intend to do something about it [Female, 43, dietitian]

e. The patient's education is more effective if it corresponds to a structured approach that is implemented step-by-step [Female, 43, dietitian]

f. Knowledge of chronic disease is essential in order to practice TPE [Female, 3I, dietitian]

Abbreviation: TPE, therapeutic patient education.

They became aware of the role of the patient's environment in facilitating or hindering the management of chronic illness ( $n=11,17$ quotations, c). The HPs recognized the added value of working as a multidisciplinary team, which they considered a lever for improving care $(n=10,16$ quotations, d). They realized the importance of recognizing their limits and being able to hand things over to other members of the team or network when necessary ( $n=2$, two quotations, e). Chronic disease was recognized in all its complexity $(n=2$, two quotations, f) (Box 5).

\section{Educational relationship between the patient and caregiver}

This concerns HP perception of the educational nature of TPE. The HPs identified their educational role in the therapeutic relationship, which consists of facilitating the patient's acquisition of abilities and competencies by creating conditions conducive to learning $(n=17,36$ quotations, a). The patient was considered an agent in his own behavior change, capable of taking an active role in decision-making and the care process ( $\mathrm{n}=11,13$ quotations, $\mathrm{b})$. The HPs recognized the patient's right to make mistakes as he learned $(n=3$, four quotations, c). They pointed out the importance of adjusting educational interventions to the patient's knowledge and representations $(n=2$, two quotations, d) and that patient motivation must come from the patient himself $(n=3$, three quotations, e). The HPs stressed the idea that chronic illness means giving up the idea of being cured and that their role
Box 5 Extracts relating to the holistic, interdisciplinary dimension of educative attitude

a. When I re-read my written remarks in the clinical case at the beginning of the course, I noticed the overly reductionist tone I used which belongs, above all, to an asymmetric model of patient care [Female, 5I, physician]

b. It is also important to point out that before the training, I only focused on weight. For me, it was a reflection of whether or not I had succeeded in my job, a real source of permanent stress that judged me as a therapist. The training allowed me to relativize and let go of this method of assessment. Throughout the training, we talked about "quality of life" rather than "losing weight", so I am trying to redirect my competencies in this direction [Female, 38, project coordinator]

c. The most conclusive point I think, or in any case it is the one that comes most clearly to mind, is the awareness of the role of close friends and relations. I am trying to make patients more aware of this, without criticizing them in any way, and asking them to talk with those close to them, suggesting they even ask one of their friends or relations to come to the consultation with them [Male, 38, dietitian]

d. At the same time, the caregiver should not work alone. They should work in an interdisciplinary network considering the wealth every approach offers in terms of the patients' care [Female, 54, dietitian]

e. Knowing my limits by passing things on [Female, 3I, dietitian]

f. Every patient is unique and sometimes complex, they come with a life history, at a given moment and we have to continuously adapt to this [Female, 48, nurse]

was to help patients live as well as possible with chronic illness ( $n=4$, five quotations, f). One HP stressed the importance of seeing the patient as an actor capable of making health choices ( $\mathrm{n}=1$, one quotation, $\mathrm{g}$ ) (Box 6).

\section{Ethical relationship}

These are the perceived conditions for a good, sustainable TPE relationship that respects the patient and his loved ones. TPE requires a transition from a directive, paternalistic approach to a recognition that the patient is a full-fledged partner in his care $(n=12,24$ quotations, a). The participants said that they had underestimated the patients' experience and suggested giving greater weight to the patients' experience with their illness by listening to them more $(\mathrm{n}=11,16$ quotations, b). The participants pointed out the personalized nature of the care, which should be adapted to the patient's abilities, experience and condition (including his psychological condition; $\mathrm{n}=10,12$ quotations, c). The patient's free, informed choices should be considered a central element in his care $(n=8,10$ quotations, d). TPE caused the HPs to reconsider their view of the clinical situation and the objectives, which might differ from the view of the patient himself. It thus became important to them to reconcile the different views ( $n=8,13$ quotations, e). 
Box 6 Extracts relating to the "educational relationship" dimension of educative attitude

a. I recognize a change in my role as a healer, of someone who facilitates change aimed at transferring the appropriate skills. Instead of prescribing and instructing the patient, I focus on the development of the patient's autonomy [Female, 5I, physician]

b. I have understood the need to take the time to enable patients to define their own standard of health by themselves, allowing them to determine their own objectives in terms of quality of life before setting a weight objective. I have indeed learned something important: you should not substitute yourself for the patient [Female, 54, dietitian]

c. The counselor must instill a feeling of trust in the patient; we were not at school anymore, giving out reports and punishments! The patient has the right to get things wrong, they will not be judged. The counselor must ensure they support them in their learning by raising their self-esteem and emphasizing all the positive points [Female, 48, nurse]

d. For me, I became aware of the fact that patients come with their perceptions of what their disease is [Female, 45, nurse]

e. A patient's motivation can only come from within, everyone has their own internal driving forces and their own list of priorities [Female, 5I, nurse]

f. The module shed light on the following point: giving up the idea of healing seemed to me to be a key concept resulting in a very different approach [Female, 38, project coordinator]

g. However, my approach to patients is changing; I am trying to see them as actors capable of making choices for their health or quality of life [Female, 48, nurse]

The HPs talked about the value of seeing the person as being at the center of his care, rather than just an organ or a disease ( $n=7$, nine quotations, $\mathrm{f}$ ). They also pointed out the importance of having a nonjudgmental, positive therapeutic relationship with the patient ( $\mathrm{n}=7$, eight quotations, $\mathrm{g}$ ). The participants stressed the need to base the care relationship on trust and transparency, in order to create a positive climate of dialog and collaboration ( $\mathrm{n}=6$, seven quotations, $\mathrm{h}$ ). They recognized that humility is needed to get there $(n=2$, two quotations, i) (Box 7).

\section{Characterizing the educative attitude}

Based on the abovementioned categories and using the methods described in the "Methods" section, we laid out the content elements in the form of statements on educative attitude (Table 3) that might be used as an aid, for example, in evaluating the educative attitude of HPs. Note that these statements come directly from the HPs themselves. There are no new elements from readings or other studies.

\section{Discussion and conclusion Discussion}

This study looked at the changes in thinking experienced by HPs enrolled in a TPE training program. The research
Box 7 Extracts relating to the "ethical relationship" dimension of educative attitude

a. The rather "fatherly" view I had of my profession in the beginning ("I know what's good for you") has evolved throughout my career toward greater respect and kindness toward the patient, but I understand now that without the patient, I cannot do anything. I now realize that if the patient is an active part of the plan, you will get better results [Female, 48, nurse]

b. I realize that, during the consultations, I underestimated the patient's experience despite the information they gave me [Female, 54, dietitian]

c. The adaptation of the caregiver to the patient: adopting a flexible and personalized approach so that it corresponds better to what the patient wants, so that they can take an active role in caring for their condition [Female, 28, project coordinator]

d. I often remind myself of the importance of the patient's autonomy and respect for the freedom of choice, as long as it is an informed choice [Female, 5I, physician]

e. When I am with my patients, the debate about "normality" makes me think that I should ask them what a normal situation would be for them, in what way their current situation is abnormal, how this normal situation would be different from a so-called "ideal" situation [Male, 38, dietitian]

f. Each patient we meet is a unique person with their own sensitivities and the work we do is in relation to a human being. This demands continuous adaptation and taking a step back so that we can better help these patients [Female, 54, dietitian]

g. The caregiver must maintain a dialogue, without ever making a judgment. It is the patient who knows what suits them. Communication must be non-confrontational [Female, 54, dietitian]

h. To achieve this, it is necessary to establish a climate of trust and transparency regarding what we do with/for them. The patient must feel empowered and be a co-actor [Female, 54, dietitian] i. A good dose of humility is required [Male, 38, dietitian]

design was pragmatic and based on an ascending approach and on the perceptions of HPs who were novices in TPE and had a range of experiences in managing chronic illnesses (as estimated by the age of the sample, since data on the length of time working were not collected) at two sites (Nancy and Liege) with very different political and legal frameworks for TPE. From the perceptions of these HPs, we were able to identify seven dimensions of educative attitude. They provide a broad view of educative attitude, which should be considered a key component of TPE competency. A comparison with the literature confirms the theoretical validity of our results.

\section{Is TPE time consuming?}

Professionals often report that a lack of time is an obstacle to effective, appropriate TPE. ${ }^{11,12,31}$ It has been shown, however, that a patient-centered approach and collaborative care can improve health outcomes without longer patient visits. ${ }^{32}$ Our study suggests that what is needed is 
Table 3 Statements regarding the characterization of the educative attitude

I. Concerning the relationship with time, educative attitude in the field of TPE is characterized by recognition of

- the need to take time for activities involving informing the patient of the diagnosis, patient identification, definition of a care plan;

- the possibility of postponing a TPE activity if the patient is not ready or to increase their motivation before undertaking the activity;

- the need to adapt the TPE to the patient's psychological readiness and the caregiver's need to be flexible and adaptable;

- the fact that chronic illness involves a long-term relationship (patient's illness for life);

- the need to situate one's intervention in relation to the patient's life history and their medical treatment.

2. Concerning the benefits of TPE practice for the caregiver, the educative attitude in the field of TPE is characterized by the recognition that TPE

- helps reinforce the caregiver's capacity for action in relation to the chronic patient;

- helps caregivers overcome the feeling of powerlessness and helps the caregiver get out of a dead-end/overcome an obstacle;

- allows the caregiver to have a more positive approach to their job (no longer being obliged to have a result-oriented approach);

- legitimizes (by giving real power) some of the caregiver's activities (for instance, asking about the patient's life history);

- helps improve the quality of the caregiver's work life;

- improves the caregiver's motivation.

3. Concerning the emotions, the educative attitude in the field of TPE is characterized by the recognition that TPE

- requires identifying and being aware of one's emotions in order to avoid transference and projection;

- requires accepting and recognizing the patient's emotions;

- requires an adjustment in the caregiver's thoughts, emotions and actions (toward authenticity and coherence);

- requires acknowledging that patients' resistance is an integral part of their development with regard to their illness;

- helps the caregiver recognize the impact of their verbal and nonverbal attitudes on the therapeutic relationship;

- helps the caregiver be more humble and more careful about their knowledge with regard to the patient;

- helps make caregivers more thoughtful about their professional practice.

4. Concerning the professionalizing nature of TPE, the educative attitude in the field of TPE is characterized by the recognition that TPE

- is more than just supplying information;

- requires trained, competent caregivers; in other words, TPE cannot be improvised;

- formalizes certain activities undertaken implicitly by caregivers;

- relies on an approach that acknowledges the essential stages such as assessment and educational diagnosis as therapeutic acts;

- requires in-depth biomedical knowledge of a specific chronic disease.

5. Concerning the holistic, interdisciplinary approach to the patient, the educative attitude in the field of TPE is characterized by the recognition that

- the aims of TPE are the individual's QOL and health;

- TPE objectives, learning activities and indicators are situated in the biopsychosocial sphere;

- only a holistic approach to the patient is effective (vs compartmentalization or division): the illness is the result of a set of environmental and biopsychosocial determining factors;

- close friends and relations must be considered as a determining factor in the illness and a resource or obstacle to care;

- chronic illness requires recourse to health care professionals specializing in different areas and interdisciplinary approach;

- caregivers have their own limits with regard to patients and it is sometimes necessary to refer the patient to someone else or work with other caregivers.

6. Concerning the educational nature of the therapeutic relationship, the educative attitude in the field of TPE is characterized by the recognition that

- the caregiver's role changes from a curative to an educational one;

- the educational role consists of learning to create, develop and recognize resources, facilitate learning and establish the right conditions for learning, to inform the patient so that they can make their own health choices;

- making mistakes is an integral part of learning, including in the learning associated with TPE;

- it is important to use the patient's knowledge and perceptions of the illness as a starting point;

- the patient is solely responsible for changing their own behavior (active position of the patient);

- the patient is capable of making choices (patient's competence);

- the patient's internal motivation must be stimulated.

7. Concerning the ethical relationship, the educative attitude in the field of TPE is characterized by the recognition that

- above all, we are caring for a human being and not an organ/illness;

- TPE involves the following values: being nonjudgmental, positive, trustworthy, transparent and humble;

- TPE requires changing from an interventionist mode to a deliberative mode, ie, partnership;

- the patient must be recognized for who they are (personalized approach);

- the patient is an expert in the experience of his illness;

- the patient is free to make their own health choices, and the caregiver's job is to make that choice is an informed one;

- the patient's view can be different from the caregiver's, especially with regard to therapeutic objectives.

Abbreviations: TPE, therapeutic patient education; QOL, quality of life.

not more time for TPE, but a different relationship with time. More specifically, caregivers need to spend time with the patient on activities such as educational diagnosis and assessment, which are often neglected, and better adapt activities to the patient's psychology. It makes no educational sense to invite patients to TPE workshops if they are not ready for it. We note that few participants reacted to or gave quotations that would fit this category of 
educative attitude. Hence, it is something that the training process should focus on.

\section{Personal benefits of TPE practice}

Numerous studies have reported the need for HPs to understand the importance of, and be aware of, TPE. ${ }^{33,34}$ The results of our study go even further, emphasizing that when caregivers see the personal benefits of TPE, their job satisfaction/motivation and the quality of their working life improve. Since Rosentstock's ${ }^{35}$ health psychology models have taught us that recognizing the benefits of taking action is crucial for implementing that action, some professionals go even further by acknowledging that TPE helps them gain, or regain, a capacity for action with the patient - that is, it empowers the HPs themselves. That conviction needs to be reinforced, since few of the participants in our study mentioned those results unsolicited. We also note that the participants mentioned only the personal benefits of TPE, while Anderson et $\mathrm{al}^{23}$ pointed out the benefits of the educational approach to society and the quality of care. This is no doubt due to the method used to collect the data, which focused on the personal transformation experienced by the people questioned. The legitimization of educational activities is another important point reported by the participants that is worth emphasizing. Indeed, without the sanction of TPE practice, professionals run the risk of being frustrated or unable to fully practice their educational activities. ${ }^{36}$

\section{Emotional dimension}

The care relationship can no longer be considered a purely intellectual one. Patient and caregiver emotions must be considered an integral part of the therapeutic relationship and cannot be denied. HPs have often been trained, and have (explicitly or implicitly) learned, to deny their emotions, to prevent the latter from compromising their decision-making ability and objectivity. As a result, HPs tend to avoid emotional subjects by focusing on the technical aspects of the treatment. Training should address how to manage one's emotions, and it should be considered a necessary skill. ${ }^{37}$ Moreover, Berg $^{38}$ showed that having an empathic psychotherapeutic attitude and understanding the mechanisms underlying patient resistance may result in an increased preference for using TPE in professional practice. Finally, we observed that the educative attitude led most participants to an introspective approach, which is confirmed by the results of other studies. Mikkonen and Hynynen ${ }^{27}$ considered introspection a prerequisite to TPE, a view that seems fairly well-represented in our study results.

\section{Holistic dimension of care}

Our results indicate how important it is that caregivers recognize the need for, and be open to, a holistic, environmental-biopsychosocial ${ }^{39}$ approach to care, as was reported by Blakeman et al. ${ }^{15}$ That aspect of educative attitude was recognized by a majority of the participants interviewed; it is a real challenge for professionals to orient themselves toward the more psychological and emotional aspects of care and quality of life issues. ${ }^{21}$ Yet, failing to place the patient and his illness in a broader life context may expose him to accusations of noncompliance, ${ }^{40}$ relegating him to the status of "bad patient". From this perspective, Rogers ${ }^{41}$ calls for unconditional acceptance of patients, and thus, professionals should refrain from any kind of moral or ethical judgments and cultivate intellectual acceptance of the patient when they meet. In addition, in this holistic approach, it is important that professionals develop a positive attitude about involvement by the patient's loved ones ${ }^{42}$ - who can be considered a lever for or obstacle to TPE. A natural extension of the holistic approach is to consider the need for interdisciplinarity and recognition of one's professional limits. In our study, however, a minority of HPs mentioned such recognition unsolicited, despite the fact that it is essential for evolving from a multidisciplinary approach to true interdisciplinarity. ${ }^{43}$

\section{Educational relationship dimension}

TPE requires HPs to evolve from an advising relationship to an educational relationship. ${ }^{27}$ Patients need to play an active role in their own care. ${ }^{24}$ If patients are to play an active role, they must be considered capable of making choices and acting on behalf of their own health. Wu et al, ${ }^{44}$ however, showed that nurses saw patients as less capable of performing self-care than did the patients themselves. HPs asked for help and support in fulfilling the educator function, while they felt more secure in their previous position as experts. ${ }^{45}$ Hult et $\mathrm{a}^{16}$ reinforced this idea as follows:

There is a strong need to focus on the parts of the pedagogical work and to encourage and support the development of professional pedagogical knowledge.

The challenge is to demonstrate to HPs the value of bringing education science to health care roles. Although roughly half of our respondents included this idea of the caregiver's educational role, that role seems to be unclear to many HPs.

\section{Professionalizing dimension of TPE}

Our results show that HPs recognize the importance of and need for specific TPE training, which is consistent with 
the results of previous studies..$^{23,46}$ That attitude requires, however, that HPs know and prioritize their patient education responsibilities ${ }^{47}$ and recognize that education is a scientific health care approach. That education mission must be treated as complementary to specialized biomedical knowledge of the disease.

\section{Ethical dimension of care}

The ethical dimension of educative attitude consists of respecting and recognizing the patient as a person with all the considerations that entail, including the need to better identify and understand the patient's own ideas, wishes and perceptions (he should be seen as a full-fledged person), ${ }^{15}$ and the acknowledgment that professionals and patients are equal and have different types of expertise. ${ }^{27}$ It also requires recognizing the patient's ability to take responsibility for his health and the patient's freedom. ${ }^{48}$ For patients to be able to make their own choices, however, HPs must give them the information they need to ensure that those choices are informed ones, ${ }^{49}$ which requires good knowledge of the disease. One important point to note regarding the fact that HPs can sometimes overestimate how much they know about the patient, perhaps because they incorrectly interpret what the patient says or because they tend not to listen actively to the patient. ${ }^{50} \mathrm{TPE}$ requires that HPs ask themselves how they can help the patient achieve their own health goals. ${ }^{51}$

\section{General comments}

The design of this study is original in that it explores what might be called a hidden curriculum, that is, the participant attitudes and values that are learned/internalized implicitly yet not stated explicitly as formal training objectives. ${ }^{52}$ Attitude change is rarely discussed in either TPE training programs or recommendations on the subject. Given the importance of attitude to educational competency, it seems necessary to bring educative attitude out of the shadows and into the light.

Indeed, an educative attitude seems essential for managing chronic illnesses.

TPE that focuses on patients' daily lives and psychosocial environment is considered the cornerstone of chronic disease management. ${ }^{39}$

While the primary task of HPs is to help patients develop the skills needed to cope with their disease in daily life, caregiver-educators must change their views, perceptions and beliefs about disease, the care relationship and the patient. This is especially true, for example, with obesity, which demands few technical skills of the patient but a great deal of effort in adapting to the disease. This requires that HPs take a new view of their role. ${ }^{39}$

One dimension of educative attitude that is missing from our results is, perhaps, that of "care," understood as the HP's support in helping the patient cope with the psychological difficulties caused by the treatment, the disease and the consequences of the disease. ${ }^{53}$ In Europe - and France, in particular - there is a distinction between TPE and support activities, the first being centered on learning and the second on psychological support for individuals. ${ }^{54}$ Yet, some authors point out that these concepts are complementary when it comes to providing patients with optimal care, in terms of both their health and their quality of life. ${ }^{55}$ Such observations demand further study to understand the reasons for this split.

Note that the seven dimensions of educative attitude should be thought of as forming a complementary whole. Of course, that goes beyond the "educational" dimension and requires that HPs truly reconsider how they view their role, the care relationship and the principles that underlie it. If we succeed in changing these perceptions, if we engage HPs in this type of reasoning, then according to the theories of Fishbein and Ajzen, ${ }^{56}$ in particular, such changes will lead to a change in professional practices that will enable them to regain a certain capacity for action with patients.

\section{Limitations of the study}

This study has several limitations. 1) The first part of the information collected to identify the characteristics of educative attitude was derived from the training program participants' evaluations and may, therefore, be colored by a sort of social desirability in the participants' responses. 2) One researcher did the majority of the data collection, analysis and quotation extraction. There were, however, regular exchanges with the working group to ensure better validation and triangulation in the operations conducted. 3) The majority of the respondents were nurses who worked in an urban hospital setting. The results are, therefore, not representative of the wide range of potential TPE training program beneficiaries. Moreover, while the chronic diseases included in the study were varied, we did not cover all chronic diseases and our study is therefore exploratory. 4) The results reflect a fragmented view of educative attitude, with the seven dimensions presented one by one. While the connections between the various dimensions should be identified, it will require additional studies. Concept maps ${ }^{57}$ might be a good tool for that purpose. 5) If we talk about 
changes in thinking experienced by health care professionals, our study cannot be considered to be a pre/posttest design. Our study is exploratory and further studies will be carried out to assess how health care professional educative attitude evolve during training.

\section{Future prospects and practical implications}

The statements that characterize educative attitude (Table 3) are central to our study, since they can be used as a benchmark for evaluating educative attitude in TPE training programs. These statements can be used to create a space for dialogue on the changes in thinking experienced by professionals in this type of training. Table 3 might also be used for working with care teams on these dimensions of attitude, asking where team members see themselves in terms of the different dimensions; this could help identify and clarify the reasons for any tensions between professionals on the same team. ${ }^{58}$

The approach for characterizing educative attitude proposed in this article calls for further study: 1) validation via quantitative evaluation to test the tool's psychometric characteristics; 2) comparing the responses with other key actors or stakeholders such as patients and TPE trainers, to ensure consistency between the trainers', beneficiaries' (caregivers') and final beneficiaries' (ie, patients') views.

\section{Conclusion}

TPE programs can lead to changes in HPs' attitudes, ${ }^{33,59,60}$ and several studies have suggested that this attitude change helps strengthen HPs' self-management/TPE practices. ${ }^{18,61}$ In this context, educative attitude is a key resource in educational competency and TPE practices and should be included in TPE recommendations. This study highlights and identifies the characteristics of educative attitude, offering a broad view of the concept. It is important that HPs adopt this attitude in all its dimensions, to ensure that their practices and behavior are in keeping with current social and health care needs and developments. While training is a major lever for that, it must not be considered the only option; thought should be given to educative attitude wherever the conditions for its optimal development exist.

\section{Acknowledgments}

The authors thank all the participants who agreed to share their experiences. The coauthors also thank Céline Crutze for her invaluable help in data analysis and Adelin Albert for his significant contribution to editing and translation, and his careful rereading, which helped bring greater clarity and focus to the article.

\section{Disclosure}

The authors report no conflicts of interest in this work.

\section{References}

1. World Health Organization. Europe Report Therapeutic Patient Education - Continuing Education Programmes for Health Care Providers in the Field of Chronic Disease. Copenhagen, Denmark: WHO; 1998.

2. Lagger G, Pataky Z, Golay A. Efficacy of therapeutic patient education in chronic diseases and obesity. Patient Educ Couns. 2010;79(3): 283-286.

3. Deccache A, Aujoulat IA. European perspective: common developments, differences and challenges in patient education. Patient Educ Couns. 2001;44(1):7-14.

4. Tardif J. L'évaluation des compétences. Documenter le parcours de développement. Montréal, Canada: Chenelière Education; 2006.

5. Institut national de préventionetd'éducation pour la santé. Elaboration d'un référentiel de compétencesenéducationthérapeutique du patient. Le référentiel des praticiens. 2011. Available from: www.inpes.sante. $\mathrm{fr} /$ referentiel-competences-ETP/pdf/referentiel-praticien.pdf. Accessed February 17, 2017.

6. Ajzen I. The theory of planned behavior. Organ Behav Hum Decis Process. 1991;50:179-211.

7. Rosenberg MJ, Hovland CI. Attitude Organization and Change: An Analysis of Consistency among Attitude Components. New Haven: Yale University Press; 1960.

8. Fazio RH, Olson MA. Attitudes: Foundations, Functions, and Consequences. The Sage Handbook of Social Psychology. London: Sage; 2003.

9. Eagly AH, Chaiken S. The Psychology of Attitudes. Fort Worth, TX: Harcourt, Brace, Jovanovich; 1993.

10. Eagly AH, Chaiken S. The advantages of an inclusive definition of attitude. Soc Cogn. 2007;25(5):582-602.

11. Cianciara D, Miller M. Physicians's attitude toward patient education. Przeglagd Epidemiol. 2003;57(3):531-540.

12. Aghakhani N, Nia HS, Ranjbar H, Rahbar N, Beheshti Z. Nurses' attitude to patient education barriers in educational hospitals of Urmia University of Medical Sciences. Iran J Nurs Midwifery Res. 2012;17(1): 12-15.

13. Funnell MM, Anderson RM, Nwankwo R, et al. A study of certified diabetes educators: influences and barriers. Diabetes Educ. 2006;32(3): 359-362.

14. Merle V, Tavolacci MP, Moreau A, et al. What factors influence healthcare professionals' opinion and attitude regarding information for patients about hospital infection? J Hosp Infect. 2007;66(3):269-274.

15. Blakeman T, Macdonald W, Bower P, Gately C, Chew-Graham C. A qualitative study of GPs' attitudes to self-management of chronic disease. Br J Gen Pract. 2006;56(527):407-414.

16. Hult H, LindbladFridh M, Lindh Falk A, Thörne K. Pedagogical processes in healthcare: an exploratory study of pedagogic work with patients and next of kin. Educ Health. 2009;22(3):199.

17. Thorne SE, TernulfNyhlin K, Paterson BL. Attitudes toward patient expertise in chronic illness. Int J Nurs Stud. 2000;37(4):303-311.

18. Bos-Touwen I, Dijkkamp E, Kars M, Trappenburg J, De Wit N, Schuurmans M. Potential for self-management in chronic care: nurses' assessments of patients. Nurs Res. 2015;64(4):282-290.

19. Norris M, Kilbride C. From dictatorship to a reluctant democracy: stroke therapists talking about self-management. Disabil Rehabil. 2014;36(1): 32-38.

20. Lake AJ, Staiger PK. Seeking the views of health professionals on translating chronic disease self-management models into practice. Patient Educ Couns. 2010;79(1):62-68. 
21. Clark NM, Stoll S, Youatt EJ, Sweetman M, Derry R, Gorelick A. Fostering epilepsy self management: the perspectives of professionals. Epilepsy Behav. 2010;19(3):255-263.

22. Roussel S, Deccache A. Various representations of concepts in therapeutic patient education among healthcare professionals: reflections and perspectives. Educ Ther Patient/Ther Patient Educ. 2012;4(2): S401-S408.

23. Anderson RM, Fitzgerald JT, Funnell MM, Gruppen LD. The third version of the diabetes attitude scale. Diabetes Care. 1998;21(9): 1403-1407.

24. Hibbard JH, Collins PA, Mahoney E, Baker LH. The development and testing of a measure assessing clinician beliefs about patient selfmanagement. Health Expect. 2010;13(1):65-72.

25. Linn LS, Lewis CE. Attitudes toward self-care among practicing physicians. Med Care. 1979;17(2):183-190.

26. Garvey F, Wigram T, Balakumar T. Measuring general hospital staff attitudes towards people with learning disabilities. Nurs Times. 2010; 106(31):10-12.

27. Mikkonen I, Hynynen MA. Health care professionals' views about supporting patients' self-management. Health Educ. 2012;112(5): 396-405.

28. Clandinin DJ, Connelly FM. Narrative Inquiry: Experience and Story in Qualitative Research. San Francisco: Jossey-Bass; 2000.

29. Neuendorf KA. The Content Analysis Guidebook. Thousand Oaks, CA: Sage Publications; 2002.

30. Miles BM, Huberman AM. Qualitative Data Analysis: An Expanded Sourcebook. 2nd ed. London: Sage Publications; 1994.

31. Tapper-Jones L, Smail SA, Pill R, Davis RH. Doctors' attitudes towards patient education in the primary care consultation. Health Educ J. 1990;49:47-50.

32. Levinson W, Gorawara-Bhat R, Lamb J. A study of patient clues and physician responses in primary care and surgical settings. JAMA. 2000; 284:1021-1027.

33. Bjerrum M, Tewes M, Pedersen P. Nurses' self-reported knowledge about and attitude to nutrition - before and after a training programme. Scand J Caring Sci. 2012;26(1):81-89.

34. Swart SK, Kanny EM, Massagli TL, Engel JM. Therapists' perceptions of pediatric occupational therapy interventions in self-care. Am J Occup Ther. 1997;51(4):289-296.

35. Rosenstock I. Historical origins of the health belief model. Health Educ Behav. 1974;2(4):328-335.

36. Wilson PM, Kendall S, Brooks F. Nurses' responses to expert patients: the rhetoric and reality of self-management in long-term conditions: a grounded theory study. Int J Nurs Stud. 2006;43(7):803-818.

37. Walger O. Similarities, differences, complementarities between doctors and nurses in their interactions with the patient in the field of the diabetic patient education programs: a review of the literature. Educ Ther Patient/Ther Patient Educ. 2011;3(1):45-55.

38. Berg M. Patient education and the physician-patient relationship. J Fam Pract. 1987;24(2):169-172.

39. Ziegler O, Bertin E, Jouret B, et al. Education thérapeutique et parcours de soins de la persone obèse. Référentiel et organisation. Rapport à la Direction Générale de la Santé et à la Direction Générale de l'Offre de Soins. [Therapeutic education and health path for the obese person: Reference guide and organization]. Obésité. 2014;9(4):302-328. French.

40. Playle JF, Keeley P. Non-compliance and professional power. $J A d v$ Nurs. 1998;27:304-311.

41. Rogers C. Le développement de la personne. France: Interéditions; 2005.

42. Rotman-Pikielny P, Rabin B, Amoyal S, Mushkat Y, Zissin R, Levy Y. Participation of family members in ward rounds: attitude of medical staff, patients and relatives. Patient Educ Couns. 2007;65(2):166-170.

43. Orchard CA, Curran V, Kabene S. Creating a culture of interdisciplinary collaborative professional practice. Med Educ. 2005;10:11.
44. Wu SF, Tung HH, Liang SY, Lee MC, Yu NC. Differences in the perceptions of self-care, health education barriers and educational needs between diabetes patients and nurses. Contemp Nurse. 2014;46(2): 187-196.

45. Adolfsson ET, Smide B, Gregeby E, Fernström L, Wikblad K. Implementing empowerment group education in diabetes. Patient Educ Couns. 2004;53(3):319-324.

46. Satink T, Cup EH, de Swart BJ, Nijhuis-van der Sanden MW. Selfmanagement: challenges for allied healthcare professionals in stroke rehabilitation - a focus group study. Disabil Rehabil. 2015;37(19): $1745-1752$.

47. Bergh AL, Persson E, Karlsson J, Friberg F. Registered nurses' perceptions of conditions for patient education - focusing on aspects of competence. Scand J Caring Sci. 2014;28(3):523-536.

48. Siminerio LM, Funnell MM, Peyrot M, Rubin RR. US nurses' perceptions of their role in diabetes care: results of the cross-national diabetes attitudes wishes and needs (DAWN) study. Diabetes Educ. 2007;33(1):152-162.

49. Baay MF, Verhoeven V, Peremans L, Avonts D, Vermorken JB. General practitioners' perception of risk factors for cervical cancer development: consequences for patient education. Patient Educ Couns. 2006; 62(2):277-281

50. Deccache A, Libion F, Mossiat F, Cuvelier MC, Gagnayre R. Paired comparisons of role representations among patients and nurses in Belgian chronic disease care units. Educ Ther Patient/Ther Patient Educ. 2009;1(2):S127-S133.

51. Anderson RM, Funnell MM. Patient empowerment: reflections on the challenge of fostering the adoption of a new paradigm. Patient Educ Couns. 2005;57:153-157.

52. Hafferty FW. Beyond curriculum reform: confronting medicine's hidden curriculum. Acad Med. 1998;73(4):403-407.

53. Butler RN, Burt R, Foley KM, Morris J, Morrison RS. Palliative medicine: providing care when cure is not possible. A roundtable discussion: part I. Geriatrics. 1996;51(5):33-36.

54. Van Ballekom KP. L'éducation du patient enhôpital. L'autonomie du patient: de l'information à l'éducation Patient Education in Hospitals: From Information to Education. Report to the Fondation Roi Baudouin. Godinne: Centre d'Education du Patient; 2008.

55. Haute Autorité Sanitaire française (HAS). Rencontres HAS 2008, Éducationthérapeutique et accompagnement des patients: quels liens? Paris: 2008. Available from: http://www.has-sante.fr/portail/upload/ docs/application/pdf/2009-03/synthesetr11_vvd13-03.pdf. Accessed February 17, 2017.

56. Fishbein MA, Ajzen I. Attitude-behavior relations: a theoretical analysis and review of empirical research. Psychol Bull. 1977;84(5):888-918.

57. Nobak JD, Gowin DB. Learning How to Learn. New York: Cambridge University Press; 1989.

58. Le Rhun A, Gagnayre R, Moret L, Lombrail P. Analyse des tensions perçues par les soignantshospitaliersdans la pratique de l'éducation thérapeutique: implications pour leur supervision. [Analysis of the tensions perceived by hospital health care professionals in the practice of therapeutic patient education: implications for their supervision]. Glob Health Promot. 2013;20(S2):43-47. French.

59. Hartweg DL, Metcalfe SA. Self-care attitude changes of nursing students enrolled in a self-care curriculum - a longitudinal study. Res Nurs Health. 1986;9(4):347-353.

60. Delea D, Shrader S, Phillips C. A week-long diabetes simulation for pharmacy students. Am J Pharm Educ. 2010;74(7):130.

61. Rubak S, Sandbaek A, Lauritzen T, Borch-Johnsen K, Christensen B. General practitioners trained in motivational interviewing can positively affect the attitude to behaviour change in people with type 2 diabetes. One year follow-up of an RCT, ADDITION Denmark. Scand J Prim Health Care. 2009;27(3):172-179. 
Patient Preference and Adherence

Dovepress

\section{Publish your work in this journal}

Patient Preference and Adherence is an international, peer-reviewed, open access journal that focuses on the growing importance of patient preference and adherence throughout the therapeutic continuum. Patient satisfaction, acceptability, quality of life, compliance, persistence and their role in developing new therapeutic modalities and compounds to optimize

Submit your manuscript here: http://www.dovepress.com/patient-preference-and-adherence-journ clinical outcomes for existing disease states are major areas of interest for the journal. This journal has been accepted for indexing on PubMed Central The manuscript management system is completely online and includes a very quick and fair peer-review system, which is all easy to use. Visit http://www. dovepress.com/testimonials.php to read real quotes from published authors. 